\section{Isolated Congenital Nasal Bifid Septum Separated by a Wide Layer of Soft Tissue}

Zeynep Karacor-Altuntas ${ }^{1}$, Mehmet Akif Dündar ${ }^{2}$, Mehmet Dadaci ${ }^{1}$, Bilsev Ince ${ }^{1}$

${ }^{1}$ Department of Plastic Reconstructive and Aesthetic Surgery, Necmettin Erbakan University School of Medicine, Konya; ${ }^{2}$ Department of Ear, Nose and Throat, Necmettin Erbakan University, Konya, Turkey

\section{Correspondence: Zeynep Karacor-Altuntas}

Department of Plastic Reconstructive and Aesthetic Surgery, Necmettin Erbakan University School of Medicine, 42080 Meram, Konya, Turkey Tel: +90-332-223-60-00-7033, Fax: +90-332-323-61-81

E-mail: zeynepkaracor@yahoo.com

No potential conflict of interest relevant to this article was reported.

Received: 3 Apr 2015 • Revised: 30 Jun 2015 • Accepted: 14 Jul 2015 pISSN: 2234-6163 • elSSN: 2234-6171

http://dx.doi.org/10.5999/aps.2015.42.5.640 • Arch Plast Surg 2015;42:640-642

Copyright (C) 2015 The Korean Society of Plastic and Reconstructive Surgeons

This is an Open Access article distributed under the terms of the Creative Commons Attribution Non-Commercial License (http://creativecommons.org/licenses/by-nc/3.0/) which permits unrestricted non-commercial use, distribution, and reproduction in any medium, provided the original work is properly cited.

Congenital nasal anomalies are rare, with an incidence of $1 \%-4 \%$. These anomalies range from simple pathology, such as septal deviation or asymmetry of the nostrils, to severe problems accompanied by different craniofacial anomalies [1] Here, we report the case of a 19-year-old boy with an aesthetic problem of the nose. His physical examination revealed a depression on the supratip area of his nose. During open rhinoplasty, the cause of this depression was found to be congenital bifid septum separated by a wide layer of soft tissue. We

Fig. 1.

Wide depression on the supratip of the nose in a preoperative view. have reported this interesting case because the condition had not been diagnosed until the age of 19 years, and even then, it was diagnosed incidentally during surgery. Further, we applied specific junctional surgery to this nasal bifid septum.

A 19-year-old male patient underwent an aesthetic operation on his nose due to a cosmetic problem. He had no complaints of any other systemic disease or malformation. His physical examination revealed a wide depression in the supratip area of his nose and a small fistula in the middle of his columella (Fig. 1).

The patient underwent open rhinoplasty. A columellar incision was made in accordance with the fistula line. Upon exploration, we observed that the fistula was a blind fistula ending at the base of the septum. The fistula was completely excised between the lower cartilages, and both the lower lateral cartilages were explored. During surgical exploration, the nasal septum was found to be a single unit along $1 / 4$ of the posterior segment, while it was divided by a wide layer of fibroadipose soft tissue along $3 / 4$ of the anterior segment (Fig. 2). We removed the intervening fibroadipose soft tissue, corrected both anterior septal deviations, and joined the anterior double septum to the midline with a $4 / 0$ monofilament synthetic absorbable suture to ensure the continuation of the posterior single septum (junctional surgery) (Fig. 3). The other parts of the nose were normal. Later, routine rhinoplasty steps were performed. The lower lateral cartilages were shaped with sutures. No osteotomy was done. After closing the nasal skin, bilateral alar wedge excision was performed. The silicone nose pads were removed on the seventh day, and no complications were observed postoperatively (Fig. 4).

External nose formation begins in the fourth and fifth weeks of gestation; at this time, five identifiable primordial structures including the frontonasal prominence and the right and the left maxillary prominences are identifiable. The frontonasal prominence is responsible for nasal development during the third to tenth weeks of gestation. On the lateral aspects of the frontal prominence, neural crest cells proliferate and form the nasal placodes. The nasal placodes invaginate to form the olfactory pit, which further invaginates to form the nasal processes. Forming on the outer edge of the pits are the lateral nasal processes. Those on the inner side are the medial nasal processes. The lateral rounded angles of the medial prominence are the globular processes. These processes continue posteriorly as plates called 


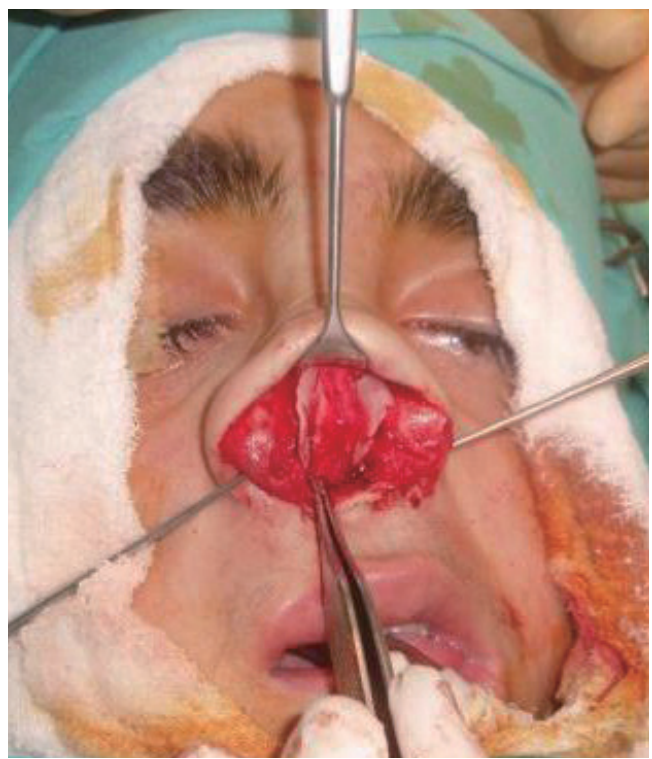

Fig. 2.

The septum was divided by a wide layer of fibroadipose soft tissue along $3 / 4$ of the anterior segment.

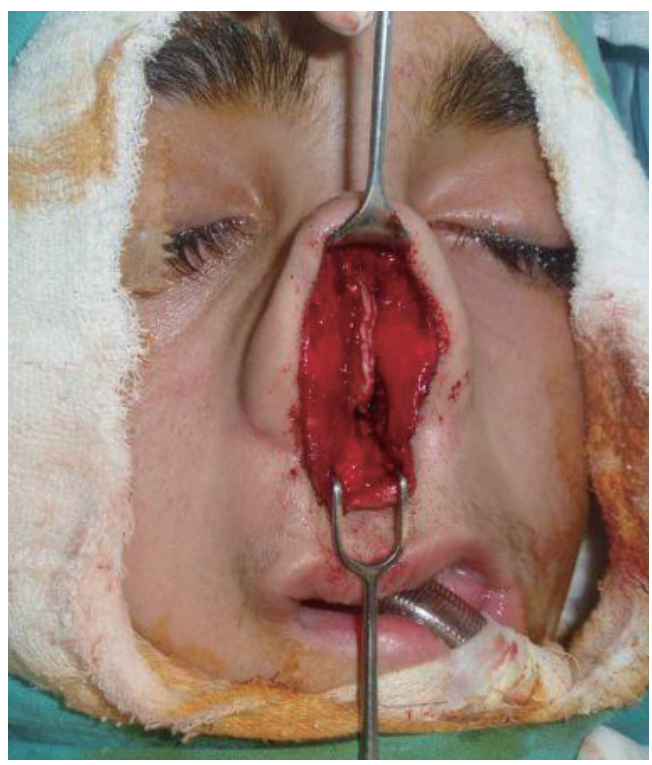

Fig. 3.

Anterior double septum was joined to the midline to ensure the continuation of the posterior single septum.

the nasal laminae. The nasal laminae fuse with the nasofrontal process in an anterior-to-posterior direction, creating the nasal septum and initially partitioning the nasal cavity into left and right divisions. The nasal septum continues to grow posteriorly and begins fusion with the palatine processes during the ninth week of gestation. Chondrification and ossification begin around the twelfth week, but ossification does not fully complete

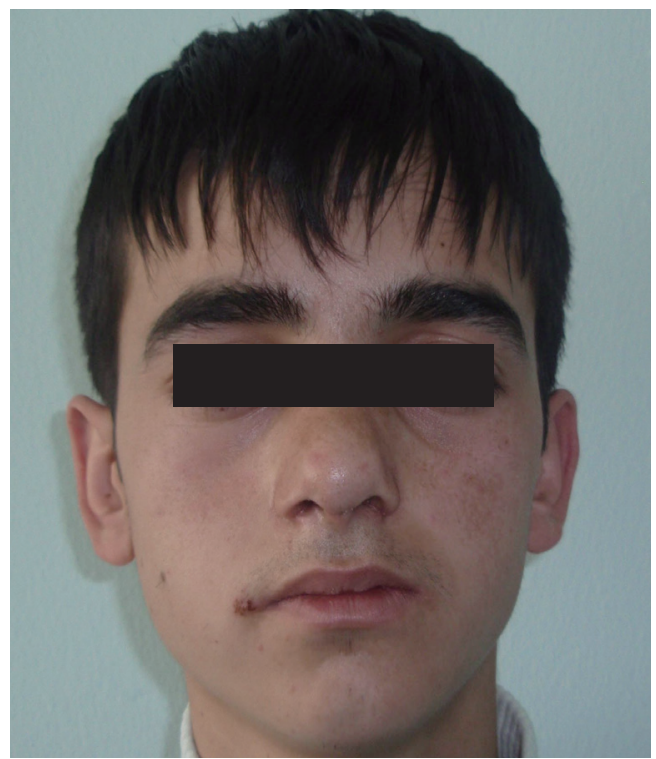

Fig. 4.

Postoperative images. until puberty [2].

Losee et al. [3] studied 261 patients with congenital nasal anomalies, excluding cleft lip nasal deformities. From this database, a systematic morphogenic classification system was devised. All congenital nasal anomalies were classified into the following scheme: (1) Type 1, hypoplasia and atrophy (62\%); (2) Type 2, hyperplasia and duplications (1\%); (3) Type 3, clefts (16\%); (4) Type 4, neoplasms and vascular anomalies (20\%).

According to this study, hyperplasia and duplications have an incidence of $1 \%$. In the literature, true nasal duplication or polyrhinia, where two distinct noses are present, each having two nostrils and nasal cavities, has been reported only twice. In addition, a few nostril duplications and one case of double columella associated with adermoid cyst and bifid caudal septum and resulting in two separate columellae, have been reported $[3,4]$.

Our case could be classified as a Type 2 anomaly (hyperplasia and duplications) according to the classification system of Losee et al. Therefore, our case is characterized as being a very rare congenital nasal anomaly due to the entry of this class with an incidence of just $1 \%$. Further, to the best of our knowledge, an isolated congenital bifid septum has not been reported thus far.

In fact, preoperative examination revealed the depression on the supratip area to be due to the excessive separation of the lower lateral cartilages from each other. However, upon exploration, we found that the lower lateral cartilages were in their normal location, while the reason for the depression 
was the congenital bifid septum separated by a wide layer of tissue.

In our opinion, the importance of this case involves the intraoperative detection of the isolated congenital nasal bifid septum, which has not been previously described, and the aesthetic repair of this congenital anomaly with a case-specific junctional surgical technique.

\section{References}

1. Hartikainen-Sorri AL, Sorri M, Vainio-Mattila J, et al. Aetiology and detection of congenital nasal deformities. Int J Pediatr Otorhinolaryngol 1983;6:83-8.

2. Neskey D, Eloy JA, Casiano RR. Nasal, septal, and turbinate anatomy and embryology. Otolaryngol Clin North Am 2009;42:193-205.

3. Losee JE, Kirschner RE, Whitaker LA, et al. Congenital nasal anomalies: a classification scheme. Plast Reconstr Surg 2004;113:676-89.

4. Rawat SS, Gupta HK. Congenital double columella. Br J Plast Surg 1975;28:153-4.

\section{Capsular Contracture after Calf Augmentation with Silicone Implant Insertion}

Bommie Florence Seo, Jong Yun Choi, Jimin Kim, Deuk Young Oh

Department of Plastic and Reconstructive Surgery, College of Medicine, The Catholic University of Korea, Seoul, Korea

Correspondence: Deuk Young $\mathrm{Oh}$

Department of Plastic and Reconstructive Surgery, College of Medicine, The Catholic University of Korea, 222 Banpo-daero, Seocho-gu, Seoul 06591, Korea

Tel: +82-2-2258-2842, Fax: +82-2-594-7230

E-mail: ohdeuk1234@hanmail.net

No potential conflict of interest relevant to this article was reported.

Received: 11 Mar 2015 • Revised: 27 May 2015 • Accepted: 9 Jun 2015 pISSN: 2234-6163 • elSSN: 2234-6171

http://dx.doi.org/10.5999/aps.2015.42.5.642 • Arch Plast Surg 2015;42:642-645 Copyright (c) 2015 The Korean Society of Plastic and Reconstructive Surgeons This is an Open Access article distributed under the terms of the Creative Commons Attribution Non-Commercial License (http://creativecommons.org/licenses/by-nc/3.0/) which permits unrestricted non-commercial use, distribution, and reproduction in any which permits unrestricted non-commercial use, distribu
medium, provided the original work is properly cited.

The legs are an aesthetically important part of the body, and an increasing number of patients desire calf-contouring procedures to improve the overall appearance of their legs. At one end of the spectrum, botulinum toxin injections are used to reduce the volume of hypertrophic calf muscles, and at the other end, silicone implants or autologous fat may be used to add volume. The shape of the calf is determined by a number of factors: the soleus and gastrocnemius musculature, the length and orientation of the bones, and the distribution of subcutaneous fat. Since Carlsen first performed calf augmentation with carved silastic foam implants inserted beneath the deep fascia of the calf in 1972, various methods of inserting silicone gel-filled implants and silicone rubber implants have been reported [1]. Inserting silicone implants into the calf has disadvantages; early postoperative complications include hematoma, seroma, wound disruption and infection, and later complications include capsular contracture, extrusion, rupture, and palpability. However, it is generally a safe procedure with a low incidence of complications [2]. Given the infrequent occurrence of complications, it is not surprising that few reports containing radiological or pathological images documenting capsular contracture have been published [3].

A 50-year-old female presented with a palpable hard implant in her left calf (Fig. 1). She complained of discomfort during walking. She had undergone calf

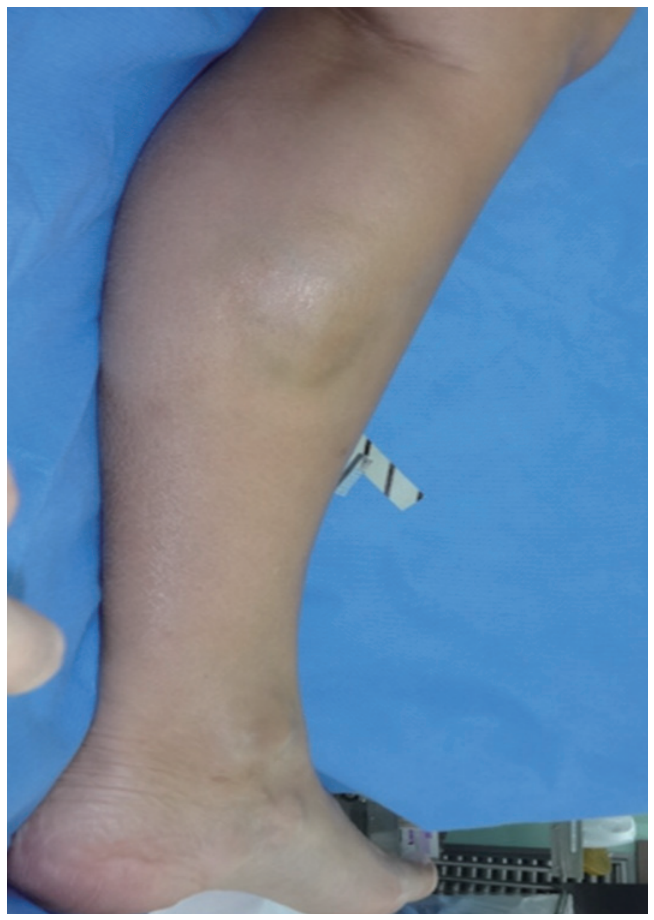

Fig. 1.

Preoperative view of the left lower leg. The implant and its capsule are visible in the medial aspect of the calf. 